ROCZNIKI HUMANISTYCZNE

Tom LXVIII, zeszyt 8 - 2020

DOI: http://dx.doi.org/10.18290/rh20688-4

\title{
TŁUMACZENIA DZIEŁ LITERACKICH KAROLA WOJTYŁY / JANA PAWŁA II NA WYBRANE JĘZYKI OBCE
}

Z uwagi na rangę Autora jako głowy Kościoła katolickiego oraz wynikającą z jego pozycji konieczność komunikacji z wiernymi na całym świecie pisma Karola Wojtyły/Jana Pawła II były wielokrotnie tłumaczone na języki obce. Translacji poddawano przede wszystkim teksty teologiczno-filozoficzne, rzadziej natomiast przekładano dzieła literackie. W 2005 r. w Warszawie został wydany obszerny tom Dzieła Jana Pawta II. Bibliografia publikacji wydanych poza Polska ${ }^{1}$, w którym odnotowano przekłady pism Ojca Świętego (literackich i teologiczno-filozoficznych) w 89 krajach na 57 języków. Rok później, czyli w 2006 r., w Krakowie do książki Przestrzeń słowa. Twórczość literacka Karola Wojtyly - Jana Pawła II ${ }^{2}$ dołączono kilkustronicowy wykaz tłumaczeń poezji i dramatów Papieża na języki obce (17 języków europejskich oraz język hebrajski).

W związku z ogłoszonym Rokiem Świętego Jana Pawła II Redakcja Roczników Humanistycznych z. 8 postanowiła uaktualnić bibliografię tłumaczeń dzieł literackich Ojca Świętego na niektóre (wybrane) języki obce (francuski, włoski, angielski, węgierski i niderlandzki). Pod uwagę brano następujące utwory literackie (według czasu powstania dzieła): Renesansowy psałterz (1938-1939), Hiob (1940), Jeremiasz (1940), Pieśń o Bogu ukrytym (1944), Brat naszego Boga (1944-1950), Pieśń o blasku wody (1950), Myśl jest przestrzenia dziwna (1952), Kamieniołom (1956), Profile Cyrenejczyka (1957), Przed sklepem jubilera (1960), Narodziny wyznawców (1961), Kościót (1962), Promieniowanie ojcostwa (misterium) (1964), Wędrówka do miejsc świętych (1965), Wigilia wielkanocna 1966 (1966), Myśląc Ojczyzna... (1974), Rozważanie o śmierci (1975), Odkupienie szuka twego kształtu, aby wejść w niepokój wszystkich ludzi (1978), Stanisław (1978), Tryptyk rzymski

\footnotetext{
${ }^{1}$ Dzieła Jana Pawła II. Bibliografia publikacji wydanych poza Polska, oprac. Anna Wolnik i Tomasz Szubiakiewicz (współpr.). Biblioteka Narodowa, Instytut Bibliograficzny, 2005.

${ }^{2}$ Przestrzeń słowa. Twórczość literacka Karola Wojtyly - Jana Pawła II, red. Zofia Zarębianka i Jan Machniak, Wydawnictwo św. Stanisława, 2006, s. 462-464.
} 
(2002). Poczynione kwerendy biblioteczne przyniosły następujące rezultaty w postaci bibliografii tłumaczeń, które podajemy według daty tłumaczenia.

\section{NA JĘZYK FRANCUSKI}

1. Wojtyła, Karol. „Chant de la splendeur de l'eau”. Poèmes. Traduit par Pierre Emmanuel et Constantin Jelenski avec la collaboration d'Anna Turowicz, Cana / Cerf, 1979.

2. Wojtyła, Karol. „La pensée est un espace étrange”. Poèmes. Traduit par Pierre Emmanuel et Constantin Jelenski avec la collaboration d'Anna Turowicz, Cana / Cerf, 1979.

3. Wojtyła, Karol. „La carrière”. Poèmes. Traduit par Pierre Emmanuel et Constantin Jelenski avec la collaboration d'Anna Turowicz, Cana / Cerf, 1979.

4. Wojtyła, Karol. „Profils du Cyrénéen”. Poèmes. Traduit par Pierre Emmanuel et Constantin Jelenski avec la collaboration d'Anna Turowicz, Cana / Cerf, 1979.

5. Wojtyła, Karol. „La naissance des confesseurs”. Poèmes. Traduit par Pierre Emmanuel et Constantin Jelenski avec la collaboration d'Anna Turowicz, Cana / Cerf, 1979.

6. Wojtyła, Karol. „L'église. Les pasteurs et les sources”. Poèmes. Traduit par Pierre Emmanuel et Constantin Jelenski avec la collaboration d'Anna Turowicz, Paris : Cana / Cerf, 1979.

7. Wojtyła, Karol. „Pérégrination aux lieux saints”. Poèmes. Traduit par Pierre Emmanuel et Constantin Jelenski avec la collaboration d'Anna Turowicz, Cana / Cerf, 1979.

8. Wojtyła, Karol. „Vigile Pascale 1966”. Poèmes. Traduit par Pierre Emmanuel et Constantin Jelenski avec la collaboration d'Anna Turowicz), Cana / Cerf, 1979.

9. Wojtyła, Karol. „Quand je pense: Patrie”. Poèmes. Traduit par Pierre Emmanuel et Constantin Jelenski avec la collaboration d'Anna Turowicz, Cana / Cerf, 1979.

10. Wojtyła, Karol (1979). „Méditation sur la mort”. Poèmes. Traduit par Pierre Emmanuel et Constantin Jelenski avec la collaboration d'Anna Turowicz, Cana / Cerf, 1979.

11. Wojtyła, Karol. Frère de notre Dieu. Ecrits sur le théâtre, Cana / Cerf, 1982.

12. Wojtyła, Karol. La boutique de l'orfèvre. Traduit par Koukou Chanska, Cerf, 1983.

13. Wojtyła, Karol. Poèmes. Traduit par Pierre Emmanuel et Constantin Jelenski avec la collaboration d'Anna Turowicz. Théâtre: La boutique de l'orfèvre. Traduit par Koukou Chanska. Frère de notre Dieu. Traduit par Zofia Bobowicz et Jean Offredo. Ecrits sur le théâtre. Cana / Cerf, 1998.

14. Jean-Paul II. Triptyque Romain. Méditations. Traduit par Agata Kalinowska-Bouvy, présentation par le Cardinal Joseph Ratzinger, avant-propos de Jean Offredo, Cana / Cerf / Fidélité / Fides, 2003. 
15. Wojtyła, Karol. Rayonnement de la paternité. Théâtre. Traduit par Yves Semen, Cerf, 2004.

16. Wojtyła, Karol. La boutique de l'orfèvre. Cerf, 2004.

Opracowała Renata Krupa

\section{NA JĘZYK WŁOSKI}

1. Wojtyła, Karol. Ritratti del Cireneo: poesie 1958 (testi introduttivi Giancarlo Mariani e Franco Cajani, Edizioni GR, 1978 (2. ed. 1983).

2. Wojtyła, Karol. Pietra di luce. Trad. Aleksandra Kurczab e Margherita Guidacci, disegni di Virgilio Guidi, Libreria Editrice Vaticana, 1979. Seria: Letteraria.

3. Wojtyła, Karol. Il sapore del pane: poesie. Trad. Aleksandra Kurczab e Margherita Guidacci, disegni di Pericle Fazzini, Libreria Editrice Vaticana, 1979. Seria: Letteraria.

4. Wojtyła, Karol. Poesie. 2 vol. (zawiera: I. Pietra di luce, disegni di V. Guidi, II. Il sapore del pane, disegni di P. Fazzini). Trad. Aleksandra Kurczab e Margherita Guidacci. Città del Vaticano: Libreria Editrice Vaticana, 1979. Tytuł alternatywny: Poesie di Karol Wojtyla da leggere e ascoltare. 2 ed. 1986.

5. Jawień, Andrzej (Karol Wojtyła). La bottega dell'orefice: meditazioni sul sacramento del matrimonio che di tanto in tanto si trasformano in dramma. Trad. Aleksandra Kurczab e Jerzy Pomianowski, Libreria Editrice Vaticana, 1979 (1 ed. di 119 esemplari numerati 1-99; 2 ed. 1979; 5 ed. 1980; 7 ed. 1983; 8 ed. 1986; 9 ed. ampliata 1988; 10 ed. 1991,11 ed. $1992 ; 12$. ed. $1994 ; 13$ ed. $1997 ; 15$ ed. 2000; 18 ed. 2004; 19 ed. 2005; 20 ed. 2006; 25 ed. 2011).

6. Wojtyla, Karol. Fratello del nostro Dio e Raggi di paternità. Drammi, disegni di Salvatore Fiume, commento di Renzo Panzone, Libreria Editrice Vaticana, 1982.

7. Wojtyła, Karol. Giobbe ed altri inediti: un dramma e sei poesie. Trad. Aleksandra Kurczab e Margherita Guidacci, disegni di Bruno Saetti, Libreria Editrice Vaticana, 1982.

8. Wojtyła, Karol. Poesie 1939-1978. Trad. Aleksandra Kurczab, Margherita Guidacci e Salvatore Fiume, a cura di Franco Zagato, San Marco, 1986.

9. Wojtyła, Karol. Entro nel cuore del dramma...: poesie. Trad. Aleksandra Kurczab e Margherita Guidacci, a cura di Franco Zagato), San Marco libri, 1991.

10. Wojtyła, Karol. La bottega dell'orefice e altri drammi. Club della della famiglia, 1991.

11. Wojtyła, Karol. Poesie. Trad. Aleksandra Kurczab e Margherita Guidacci, a cura di Giuseppe Centore, b.d.w., 1992.

12. Wojtyła, Karol. Opere letterarie: poesie e drammi. Libreria Editrice Vaticana, 1993.

13. Wojtyła, Karol (1994). Poesie. Trad. Aleksandra Kurczab e Margherita Guidacci, Newton, 1994. Seria: Grandi tascabili Newton. 
14. Wojtyła, Karol. L'opera poetica completa di Karol Wojtyła (Giovanni Paolo II), a cura di Santino Spartà, Libreria Editrice Vaticana, 1999 (2. ed. 2011; 3 ed. 2012).

15. Wojtyła, Karol. Tutte le opere letterarie: poesie, drammi e scritti sul teatro, presentazione di Giovanni Reale, saggio introduttivo Bolesław Taborski, Bompiani, 2001 ( 2 ed. 2005; 3 ed. 2011). Seria: Il pensiero occidentale.

16. Wojtyła, Karol. Il teatro rapsodico: articoli e lettere, trad. Jadwiga Radzik Lanzetta, presentazioni Domenico Galdieri, Massimo Pedroni e Luca Doninelli, Titivillus, 2003.

17. Wojtyła, Karol. Trittico romano: meditazioni, introduzione e prefazioni di Giovanni Reale, Bompiani, 2003 (2 ed. 2011). Seria: Letteraria straniera.

18. Wojtyła, Karol. Trittico romano: meditazioni. Trad. Grażyna Miller, Libreria Editrice Vaticana, 2003. Seria: Letteraria.

19. Wojtyła, Karol. Le poesie giovanili: Salterio di Davide, Libro slavo, Salterio rinascimentale: Cracovia, primavera-estate 1939. Trad. e cura Marta Burghardt, presentazione Paolo Martino). Studium, 2004. Seria: Quaderni della Libera università Maria SS. Assunta, LUMSA, Roma; 22.

20. Wojtyła, Karol. Tutte le poesie, prefazione di Giovanni Reale, Corriere della sera, 2005.

21. Wojtyła, Karol. Le mie preghiere; Le mie poesie: l'opera poetica completa con testo originale a fronte, a cura di Santino Spartà, Newton Compton, 2011. Seria: Grandi tascabili economici.

22. Wojtyła, Karol. Non c'è paura senza speranza: le preghiere e le poesie del papa che ha cambiato il mondo. Trad. Grażyna Miller, a cura di Santino Spartà, Newton Compton, 2011 (2 ed. 2011; 3 ed. 2014). Seria: saggistica.

23. Wojtyła, Karol. Poesie, a cura di Renzo Sala, disegni di Nani Tedeschi, San Pao$10,2011$.

Opracowała Monika Woźniak

\section{NA JĘZYK ANGIELSKI}

1. Wojtyła, Karol. Poezje. Poems. Trans. Jerzy Peterkiewicz, Wydawnictwo Literackie, 2005.

2. Wojtyła, Karol. Poezje. Poesie. Trans. Jerzy Peterkiewicz, Wydawnictwo Literackie, 2011.

3. Wojtyła, Karol. Poezje. Poesie. Trans. Jerzy Peterkiewicz, Wydawnictwo Literackie, 2012.

4. John Paul II. Poems. Trans. Jerzy Peterkiewicz, Wydawnictwo Literackie, 1998.

5. John Paul II. Collected Poems. Hutchinson, 1982.

6. John Paul II. The place within. The poetry of Pope John Paul II. New York : Random House, 1979. 
7. John Paul II. The place within. The poetry of Pope John Paul II. Random House, 1982.

8. Wojtyla, Karol. The place within. The poetry of Pope John Paul II. Random House, 1994.

9. Wojtyla, Karol. The place within. The poetry of Pope John Paul II. Random House; London : Hutchinson, 1995.

10. Wojtyla, Karol. The place within. The poetry of Pope John Paul II. Random House, 2000.

11. John Paul II. The jeweller's shop : a meditation on the sacrament of matrimony passing on occasion into a drama. Random House, 1980.

12. Wojtyla, Karol. The jeweller's shop : a meditation on the sacrament of matrimony passing on occasion into a drama. Ignatius Press, 1980.

13. John Paul II. The jeweller's shop : a meditation on the sacrament of matrimony passing on occasion into a drama. Hutchinson 1980.

14. John Paul II. The jeweller's shop. Samuel French, 1988.

15. Wojtyla, Karol. The jeweller's shop : a meditation on the sacrament of matrimony passing on occasion into a drama. Ignatius Press, 1992.

16. John Paul II. Easter vigil and other poems. Hutchinson, 1979.

17. John Paul II. Easter vigil and other poems. Random House, 1979.

18. John Paul II. Easter vigil and other poems. Libreria Editrice Vaticana, 1979.

19. John Paul II. Easter vigil and other poems. Arrow Books, 1979.

20. John Paul II. Roman triptych : meditations. Tryptyk rzymski: medytacje. Trans. Jerzy Peterkiewicz, Wydawnictwo Literackie, 2003.

21. John Paul II. Roman triptych : meditations. USCCB, 2003.

22. Wojtyła, Karol/John Paul II. Roman triptych: meditations. Catholic Truth Society, 2003.

23. Wojtyła, Karol/John Paul II. Collected Poems / Roman triptych. Wydawnictwo Biały Kruk, 2003.

24. John Paul II. Roman triptych: meditations. Trans. Jerzy Peterkiewicz, Wydawnictwo Literackie, 2005.

Opracowała Cecylia Galilej

\section{NA JĘZYK WĘGIERSKI}

1. János Pál pápa. Az aranymüves boltja. Elmélkedés a házasság szentségéröl, olykor drámai fordulatokkal. Trad. Balássy Péter. Agapé Kršćanska sadašnjost, 1989.

2. János Pál pápa. A mi Urunk testvére. Trad. Gimes Romána. Európa Kiadó, 1991.

3. János Pál pápa. Római triptichon: elmélkedések. Trad. Zsille Gábor et Thullner Zsuzsanna. Új Ember, 2003. 


\section{NA JĘZYK NIDERLANDZKI}

1. Wojtyla, Karol. De winkel van de juwelier. Vert. Frans van Dooren, met inl. door Michiel van der Plas, Kwadraat, 1996.

2. Johannes Paulus II. Als ik vaderland zeg: gedichten en gedachten. Vert. en red. Genade van Itterbeek-de Lille, Altiora / Omniboek, 1981.

3. Johannes Paulus II. Romeinse triptiek. Vert. Gerard Rasch, De Prom, 2003.

Opracowat Marcin Polkowski

Jak się zatem okazuje, działalność przekładowa związana z tłumaczeniem dzieł literackich Karola Wojtyły/Jana Pawła II istnieje od początku jego pontyfikatu i utrzymuje się mniej więcej do czasu Jego śmierci (najdłużej we Włoszech jeszcze przez pierwszą dekadę XXI wieku). Zainteresowaniem cieszą się najbardziej popularne utwory: poezje, sztuka Przed sklepem jubilera, dramat Brat naszego Boga i poemat Tryptyk rzymski. Pozostałe dzieła, np. młodzieńczy zbiór wierszy Renesansowy psatterz, dramat Hiob, cyk1 poetycki Profile Cyrenejczyka, Promieniowanie ojcostwa (misterium), Myślac Ojczyzna..., poemat Wigilia wielkanocna 1966, są wydawane rzadziej. Najwięcej przekładów dokonano we Francji. Opublikowano tam: poezje, Brat naszego Boga, Pieśń o blasku wody, Myśl jest przestrzenia dziwna, Profile Cyrenejczyka, Przed sklepem jubilera, Narodziny wyznawców, Kościót, Promieniowanie ojcostwa (misterium), Wędrówka do miejsc świętych, Wigilia wielkanocna 1966, Myślac Ojczyzna..., Rozważanie o śmierci, Tryptyk rzymski. We Włoszech wydano: poezje, Renesansowy psałterz, Hiob, Profile Cyrenejczyka, Przed sklepem jubilera, Promieniowanie ojcostwa, Brat naszego Boga i Tryptyk rzymski. Wersji anglojęzycznych - wydanych w Polsce, Wielkiej Brytanii, Stanach Zjednoczonych i w Rzymie - doczekały się cztery teksty (kilkakrotnie wznawiane): poezje, Przed sklepem jubilera, Wigilia wielkanocna 1966 i Tryptyk rzymski. Na Węgrzech opublikowano jedynie trzy pozycje literackie: Przed sklepem jubilera, Brat naszego Boga, Tryptyk rzymski. Podobnie też na język niderlandzki przetłumaczono trzy utwory: Przed sklepem jubilera, Myślac Ojczyzna... i Tryptyk rzymski. Podsumowując to zestawienie tłumaczeń dzieł literackich Ojca Świętego, można stwierdzić, że Jego twórczość - obfitująca w wiele cennych refleksji metafizycznych, egzystencjalnych, artystycznych itp. - nie jest w Europie i na świecie $w$ pełni poznana i doceniona. Trzeba jednak wyrazić radość z faktu, że tyle dzieł zostało już przetłumaczonych, i mieć nadzieję, że kolejnych przekładów dzieł Papieża będzie coraz więcej. 
Pragniemy wyrazić słowa podziękowania dr. Mirosławowi Stasiło z Uniwersytetu Wileńskiego, który zadał sobie trud wyszukiwania tłumaczeń dzieł literackich Karola Wojtyły/Jana Pawła II na język litewski. Jak się niestety okazało, takich tłumaczeń nie ma.

\section{Zebrata i komentarzem opatrzyła \\ Cecylia Galilej}

Instytut Językoznawstwa KUL

e-mail:cgalilej@kul.lublin.pl

ORCID: https://orcid.org/0000-0002-6379-9361 